\title{
Correction to: Melting of carbonated pelite at 5.5-15.5 GPa: implications for the origin of alkali-rich carbonatites and the deep water and carbon cycles
}

\author{
Xueqian Chen ${ }^{1} \cdot$ Meili Wang $^{1,2} \cdot$ Toru Inoue $^{3,4,5} \cdot$ Qiong Liu ${ }^{1}$ [ $\cdot$ Lifei Zhang ${ }^{1} \cdot$ Thomas Bader $^{1}$
}

Published online: 13 January 2022

(c) Springer-Verlag GmbH Germany, part of Springer Nature 2022

\section{Correction to: \\ Contributions to Mineralogy and Petrology (2022) 177:2 \\ https://doi.org/10.1007/s00410-021-01867-5}

In the original publication, Fig. 7 and Fig. 8 (and its caption) were published incorrectly and this has been corrected in this correction article. The correct Fig. 7 and Fig. 8 with caption are provided below.

The original article can be found online at https://doi.org/10.1007/ s00410-021-01867-5.

Qiong Liu

qiong.liu@pku.edu.cn

1 Key Laboratory of Orogenic Belts and Crustal Evolution, School of Earth and Space Sciences, Peking University,

Beijing 100871, People's Republic of China

2 Beijing Institute of Economics and Management, Beijing 100102, People's Republic of China

3 Geodynamics Research Center, Ehime University, 2-5 Bunkyo-cho, Matsuyama, Ehime 790-8577, Japan

4 Department of Earth and Planetary Systems Science, Hiroshima University, Higashi-Hiroshima, Hiroshima 739-8526, Japan

5 Hiroshima Institute of Plate Convergence Region Research (HiPeR), Hiroshima University, Higashi-Hiroshima, Hiroshima 739-8526, Japan 
Fig. 7 Curves that define the stability of experimental phases obtained from this study at each run condition are summarized in this figure. Grey dashed lines are the cold (Kincaid and Sacks 1997), the average (Van Keken et al. 2002) and hottest subduction trajectory (Peacock 2003), and the mantle geotherm (Akaogi et al. 1989). Dotdashed line shows the reaction of coesite $=$ stishovite $($ Zhang et al. 1996). Black dotted lines of cpx-, k-hol-, carb-, hydrous minerals-out and CAS-in are from this study. The solid black line is melt-in from this study. Experimental phase assemblages are also shown in this figure

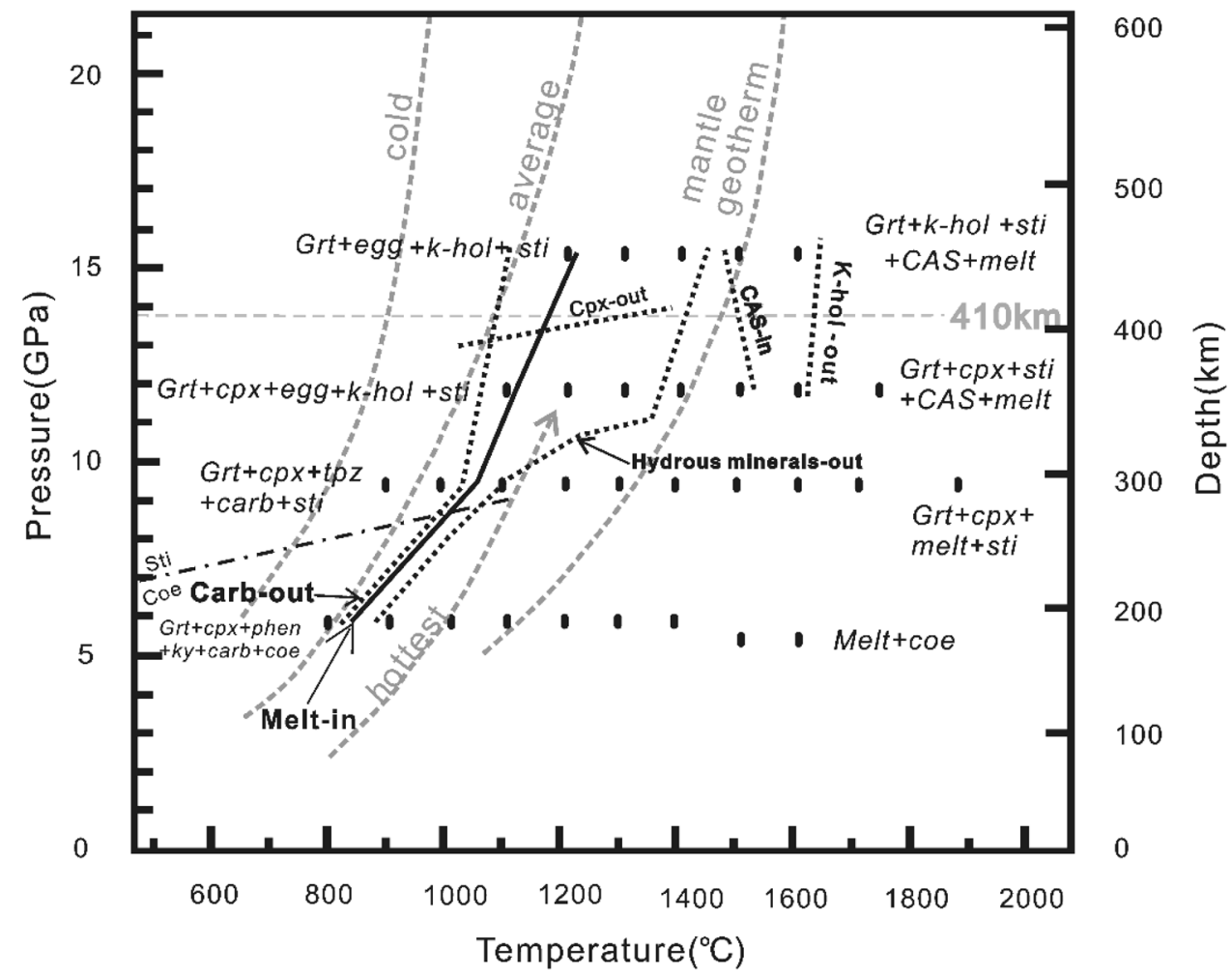




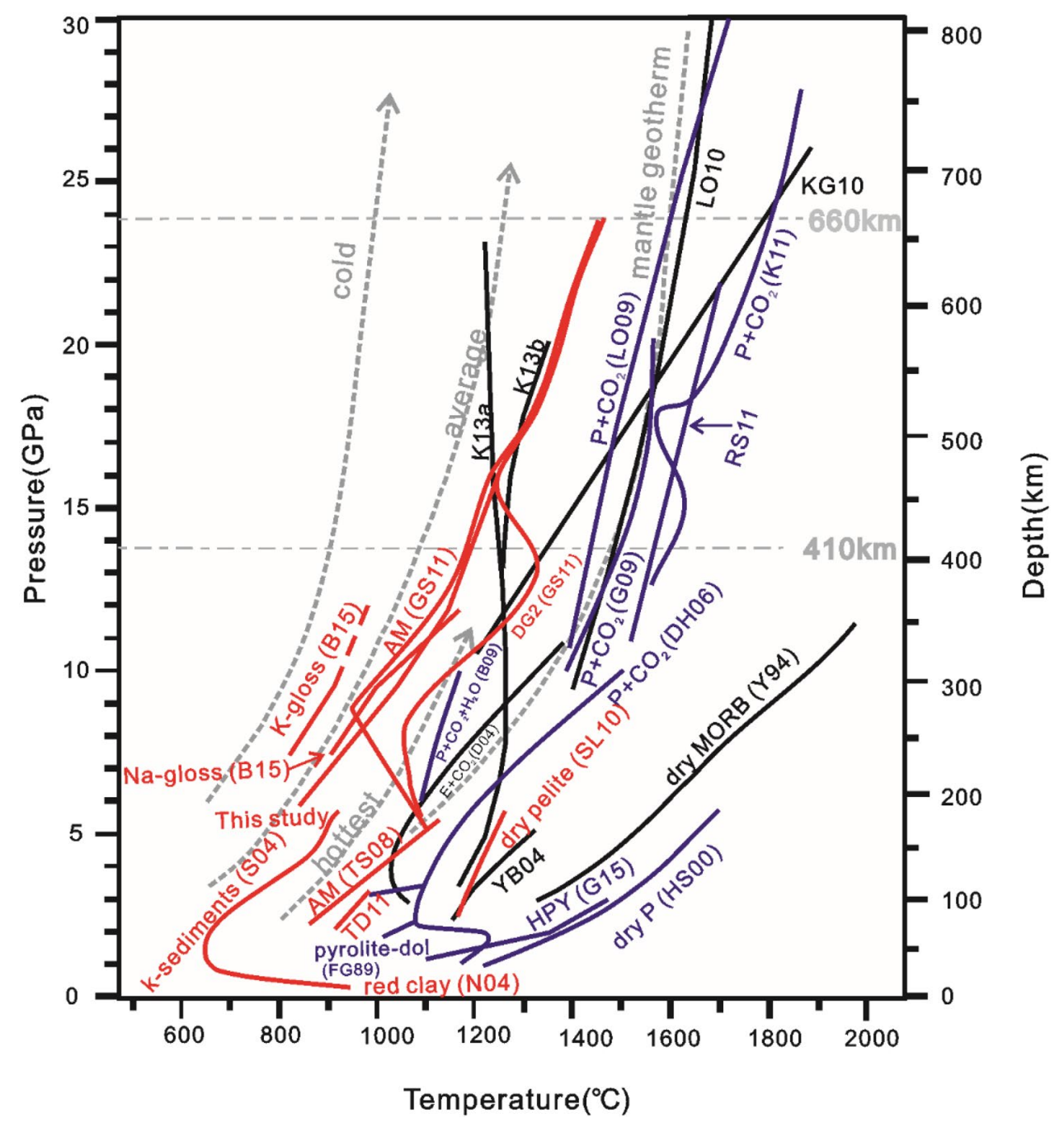

Fig. 8 Summary of solidi for (carbonated) peridotites, pyrolites, basalts, eclogites, and pelites. The P-T diagram shows typical subduction trajectories (Kincaid and Sacks 1997; van Keken et al. 2002; Peacock 2003) and the mantle geotherm (Akaogi et al. 1989). Most of the solidi of carbonated pelites lie between the average and the hottest subduction path, which demonstrates that melting of such pelites happens only when oceanic slab subduction slows down, or even stagnates, and thermal relaxation leads to a rising temperature of slab towards the mantle adiabat. Blue-(carbonated) peridotite and pyrolite: FG89 (pyrolite +5\% dolomite), Falloon and Green (1989); HS00 (dry peridotite), Hirschmann (2000); DH06 (2.5 wt\% $\mathrm{CO}_{2}$ ), Dasgupta and Hirschmann (2006); G09 (5 wt\% $\mathrm{CO}_{2}$ ), Ghosh et al. (2009); LO09 (5 wt\% $\mathrm{CO}_{2}$ ), Litasov and Ohtani (2009); K11 (CMS + 25.41 wt $\% \mathrm{CO}_{2}$ ), Keshav et al. (2011); B09 (3.63 wt $\% \mathrm{CO}_{2}+2.22 \mathrm{wt} \%$ $\mathrm{H}_{2} \mathrm{O}$ ), Brey et al. (2009); RS11 (natural samples $+5 \mathrm{wt} \% \mathrm{CO}_{2}$ ), Rohr- bach and Schmidt (2011); G15 (Hawaiian Pyrolite (HPY) + $0.2 \mathrm{wt} \%$ $\mathrm{H}_{2} \mathrm{O}$ ), Green (2015); Black-(carbonated) basalt and eclogite: D04 (5 wt $\% \mathrm{CO}_{2}$ ), Dasgupta et al. (2004); YB04 ( 11 wt\% $\left.\mathrm{CO}_{2}\right)$, Yaxley and Brey (2004); Y94 (dry MORB), Yasuda et al. (1994); K13a, $\mathrm{K} 13 \mathrm{~b}$ (dry carbonated eclogite; a, 4.4 wt $\% \mathrm{CO}_{2}$; b, 6.5\% $\mathrm{SiO}_{2}+4.4$ wt $\% \mathrm{CO}_{2}$ ), Kiseeva et al. (2013); LO10 (5 wt $\% \mathrm{CO}_{2}+$ alkali-bearing eclogite), Litasov and Ohtani (2010); KG10 (CMAS + 20.22-25.98 wt\% $\mathrm{CO}_{2}$ ), Keshav and Gudfinnsson (2010); Red-(carbonated) pelite: S04 (2.1 wt $\% \mathrm{H}_{2} \mathrm{O}$ ), Schmidt et al. (2004); TS08 (AM, $4.8 \mathrm{wt} \%$ $\mathrm{CO}_{2}+1.1 \mathrm{wt} \% \mathrm{H}_{2} \mathrm{O}$ ), Thomsen and Schmidt (2008b); GS11(AM, 4.8 wt $\% \mathrm{CO}_{2}+1.1 \mathrm{wt} \% \mathrm{H}_{2} \mathrm{O}$; DG2, $4.8 \mathrm{wt} \% \mathrm{CO}_{2}$ ), Grassi and Schmidt (2011a); SP10 (dry pelite), Spandler et al. (2010); TD11 (5.08 wt\% $\mathrm{CO}_{2}$ ), Tsuno and Dasgupta (2011); B15 (Na/K-gloss with $6 \mathrm{wt} \%$ $\mathrm{CO}_{2}+6.9 \mathrm{wt} \% \mathrm{H}_{2} \mathrm{O}$ ), Brey et al. (2015)

Publisher's Note Springer Nature remains neutral with regard to jurisdictional claims in published maps and institutional affiliations. 